\title{
Comparison of Methods and Existing Tools for the Measurement of Usability in the Web
}

\author{
Maria E. Alva O., Ana B. Martínez P., Juan M. Cueva L., \\ T. Hernán Sagástegui Ch., and Benjamín López P. \\ University of Oviedo, Department of Computer Science, Calvo Sotelo S/N, \\ 33007 Oviedo, Spain \\ \{malva360, thsagas\} acorreo.uniovi.es \\ \{belen, cueva, benjamin\} @lsi.uniovi.es
}

\begin{abstract}
This paper presents the evaluation of a group of methods and tools for the measurement of usability in software products and software artefacts in the web. The evaluation carried out consists on studying the measurement principles and dimensions considered for each one of the methods and tools, with the purpose of comparing the degree of vicinity among them and with the principles enumerated by the ISO 9241-11 standard: efficiency, effectiveness and satisfaction.
\end{abstract}

\section{Introduction}

Nowadays, usability is a fundamental factor to consider when designing a web site. According to ISO 9241-11 [14] usability is, "the degree to which a product can be used by specific users to reach specific goals with efficiency, effectiveness and satisfaction in a given use context". It is considered by many as a fundamental part to determine the quality of a software product.

The need to measure the usability of software products or web artefacts is become gradually more relevant. It is not strange, keeping in mind that the existence of a poor user interface (from the point of view of the usability) will reduce user productivity. This produces unacceptable learning times, and high error levels that will frustrate the user. In the end, the system will be rejected. There are different methods and tools aimed to measure the degree of usability of a software product or web site. However, the same measuring procedures are not used by all the methods. Some use questionnaires only, while others include additional tools that facilitate a more precise measuring.

The goal of this paper is to carry out a revision of some of the most relevant methods and tools related with the measurement of the usability of a web site. The purpose is to determine the degree of vicinity among them and with the principles enumerated by the ISO 9241-11 standard. That is, the question is to find how the principles of the standard are taken into account by these methods and tools. 


\section{Methods and Tools for the Measurement of Usability}

The methods of evaluation of usabilidad of software products and web site considered in this paper correspond to formative methods, as specified in [17], which are methods applied during the development to improve a design.

a) MUSiC [1], [9], [11], considers that usability can be evaluated through the measurement of the quality in use, measuring three components of usability: i) Measure of the Task Performance of Users. It measures the effectiveness, efficiency, productive period, and learning of the system in use, using the DRUM tool [1], [2], ii) Measure of Satisfaction It assesses the comfort and acceptability of the product the SUMI questionnaire [1], [10], iii) Cognitive workload]. It measures the mental effort required to perform a task subjectively using the SMEQ y TLX [2],[10] questionnaires or objectively way with electrodes connected to a recording system.

b) WAMMI questionnaire [4], [15], it measures user satisfaction with web sites. It is based in five factors: attractiveness, control, efficiency, utility and learning. In [15] information is added: for the assessment of individual differences and web tasks.

c) MAGICA [5], [8], this project has developed a methodology of the measurement of usability, which involves i) Measurement of user satisfaction. It makes use the WAMMI questionnaire; ii) Measurement of task completion time. It controls the time used to complete a task using the RUE metric (Relative User Effective); iii) Measurement of cognitive effort. To know the stress level the user suffers when completing a task, measured with SMEQ [1], [2]; iv) Measurement of heuristic principles. It evaluates the adhesion to heuristic principles for the web [10].

d) IsoMetrics [3], [16] it is utilized in comparison of competing products or different releases or prototypes of a software or a system. It is based on the ISO 9241-10 standard and adapted to the principles of the ISO 9241-11 standard: suitability to the task, self-description, controllability, and conformity with user expectations, error tolerance, suitability for individualization and suitability for learning.

e) Web-site QEM [12], [13] is a quantitative methodology for the evaluation of the quality in applications centred on the web. It considers four features: reliability, efficiency, usability and functionality. Concerning usability, it carries out the measurement through a questionnaire that evaluates global understandability of the site, mechanisms of help, aspects of interfaces and miscellaneous items.

f) USE [6], [7] is a questionnaire which measures usability through three dimensions (utility, easiness, and satisfaction), and four domains (hardware, software, documentation, and services). It uses the same dimensions to measure the four domains, with brief and general questions.

\section{Principles Supported by the Methods and Tools}

According to the ISO 9241-11[14] standard. The evaluation measures to consider when measuring the usability of a web artefact are effectiveness (the accuracy and completeness with which users achieve a goal with the system), efficiency (the resources expended in relation of the goal) and satisfaction (the comfort and acceptability of the user using the system). 


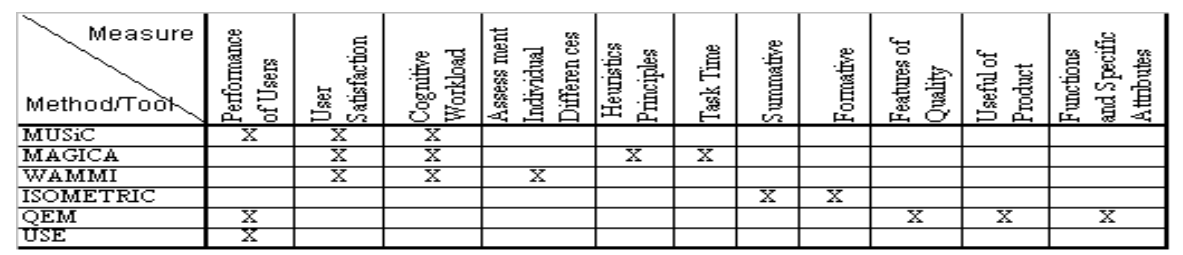

Fig. 1. Shows that measures considered more important when measuring usability $(50 \%$ of the study methods) are: performance, satisfaction and cognitive workload.

\section{Evaluation Dimensions Used in the Methods and Tools}

Once the high-priority measures in which the studied tools and methods are based were analysed (Fig. 1). The dimensions of each measure were considered in addition for each one of the methods and tools, with the purpose of establishing the vicinity among them and with the principles stated by the ISO 9241-11 standard. The results obtained can be seen in Fig. 2.



Fig. 2. Shows that the dimensions more considered for the evaluation of usability are: learning (in $83 \%$ of methods), followed by efficiency, utility, control and perception of satisfaction of the user (in 66.7\%). The efficiency is next (50\%), and finally, the effectiveness, the mental effort, and the easiness of use of the product $(33 \%)$.

\section{Conclusions}

To measure the usability of a product software has become an important purpose within the development of a product or web site. It seeks to avoid the redesign that is translated in a more difficult learning and in lost of effectiveness for the realization of the tasks. These causes lack of motivation in the user, and in many occasions the system can be rejected.

With the purpose of measuring the usability of software products at present we have methods and tools that consider the measuring in different aspects (e.g. satisfaction, performance). This allows to obtain different usability measures and therefore more information for diagnostics, and offering tools aimed to measure specific aspects of the usability 
In this work some methods and tools related with the measurement of the usability are analysed with the purpose of comparing the vicinity among them and with the principles enumerated by the ISO 9241-11 standard. From the analysis presented in this paper, we conclude that not all the examined elements are based on the principles mentioned in the standard. Thus MUSiC and MAGICA are the most coincident methods with the standard, while WAMMI for example, only defines with clarity the satisfaction and effectiveness principles. Others such as USE and IsoMetrics, although they claim to be based on them do not establish them with clarity.

In the study made it has been determined that the revised methods were designed to measure the usability of traditional software products and/or trade oriented and online sale web site. This is an indication of the importance the usability has for a web site, and also outlines the necessity of methods of this type aimed to measure the usability of web site for educational services.

\section{References}

1. Bevan, N., Macleod, M.: Usability Measurement in Context. Behaviour and Information Technology,. (1994) 13, 132,-145

2. Bevan, N.: Measuring Usability as Quality of Use. Software Quality Journal (1995) 115150

3. Gediga, G., Hamborg, K., Duentsch, I.: The IsoMetrics usability inventory: Behaviour \& Information Technology (1999). VOL. 18, NO. 3, $151 \pm$ 1644. Kirakowski, J., Claridge, N., Whitehand, R.: Human Centered Measures of Success in Web Site $4^{\text {th }}$ Conference on Human Factors and the Web Basking Ridge. USA (1998)

5. Kirakowski, J., Cierlik, B.: Measuring the Usability of Web Sites. HFRG-University College Cork, Ireland. 'Information Engineering' European Long Term Research Project 2069.

6. Lund, A.: Measuring Usability with the USE Questionnaire. STC Usability SIG NewLetter, Usability Interface (2001)

7. Lund, A. : USE Questionnaire (2002) http://www.mindspring.com/ alund/USE

8. MAGICA.: Project Summary (2003). http://arti4.vub.ac.be/previous_projects/magica.

9. Macleod, M.: Usability: Practical methods for testing and Improvement. Norwegian Computer Society Software Conference. Sandvika, Norway (1994)

10. Macleod, M.: Usability in Context: Improving Quality of Use. DITC, G Bradley and HW Hendricks (Eds.). 4th International Symposium on Human Factors. Holland (1994).

11. MUSiC 5429. Metrics for Usability Standards in Computing. ESPRIT Project 5429.

12. Olsina, L. Rossi, G.: Web Engineering: A Quantitative Methodology for Quality Evaluation and Comparison of Web Applications Thesis Doctoral, Universidad de La Plata, Argentina.

13. Olsina, L., Godoy D.,La Fuente, G., Rossi, G.: Assessing the quality of academic websites: A case study. The New Review of Hipermedia and Multimedia 5 (1999) 81-103

14. Smith, W.: ISO and ANSI- Ergonomic Standard for Computer Products. A Guide to Implementation and Compliance. (eds.), Prentice Hall Saddle, New Jersey (1996)

15. Uttl, B., Newman, C., Pikenton-Taylor C.: DO Web Usability Questionnaires Measure Web Site Usability? The Rocky Mountain Psychological Association, UT (2002.)

16. Willumeit, H., Hamborg, K., Gedica, K.: ISOMETRIC ${ }^{\mathrm{L}}$. Questionnaire for the evaluation of graphical user interfaces based on ISO 9241/10.

17. Scriven, M.. The methodology of evaluation. In R. Tyler, R. Gagne, \& M. Scriven (Eds.), Perspectives of curriculum evaluation (pp. 39-83). Chicago: Rand McNally. (1967) 